\title{
The representation of turbulent sounds in German: a government approach
}

\author{
Anna Bloch-Rozmej \\ John Paul II Catholic University of Lublin, Poland
}

\section{Introduction}

The unfolding discussion will focus on the internal representation of turbulent sounds in the phonology of German as well as pinpoint the special status of the prime defining the quality of turbulence. It will also be argued that this prime is capable of entering into special types of licensing relations, which results in specific phonetic manifestations of forms. We shall compare the effects of two processes attested in German: consonant degemination and spirantisation with a view to revealing the role of the turbulence-defining element in the two operations. Furthermore, our attention will be focused on the workings of the Obligatory Contour Principle which, as will be shown below, exerts decisive impact on prime interplay and consequently the phonetic realization of sounds and words. We shall see that segmental identity is contingent on the languagespecific interpretation of inter-element bonds.

Aware of the importance of prime autonomy in determining the manifestation of sounds, let us start with a brief outline of the fundamental segment structure principles offered by the theory of Phonological Government.

\section{Elements and segments in Government Phonology}

Within the framework of Government Phonology (Kaye, Lowenstamm and Vergnaud (1985; 1990), Harris (1994), or Gussmann (2002)), the representation of segments is strictly dependent on the number, type and configuration of phonological primes. Put differently, the melodic plane constitutes a hierarchical multi-tiered construct, where each autonomous element, residing on its own tier, is directly associated with a skeletal position. The establishment of an association line between a prime and a slot results in the phonetic manifestation of the element. We shall illustrate this situation with a structure of vocalic expressions as proposed in Harris $(1994,101)$ : 
(1) The melodic plane

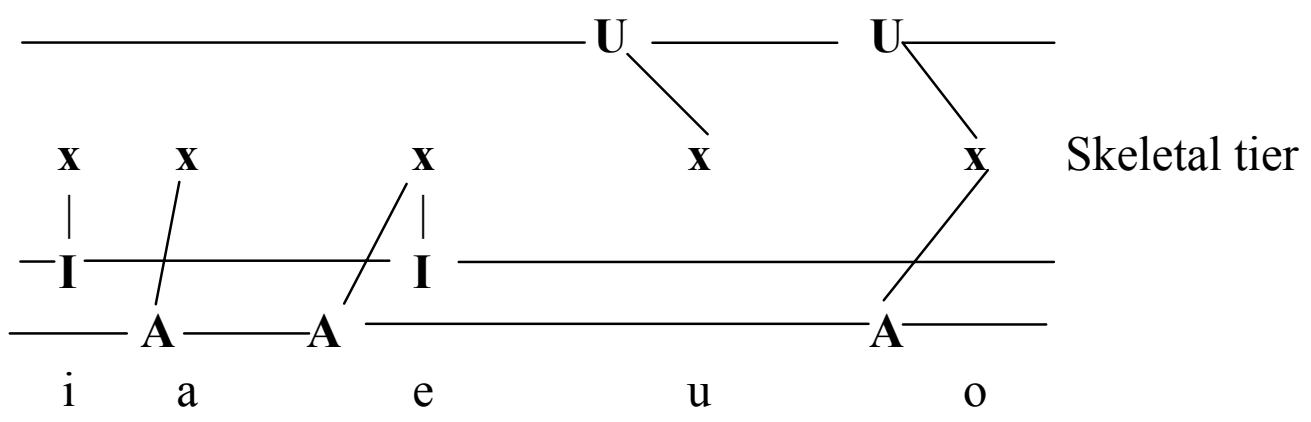

As depicted in (1), a melodic expression can consist of one or more elements. Government Phonology proposes that primes constituting melodic entities should correspond to identifiable phonetic properties, each having its own unique interpretation at any level of derivation. In the case of multi - element combinations, the phonetic outcome is contingent on the properties contributed by their constituent members. Below in (2), a list of phonological primes is supplied together with their salient properties.

\section{(2) Element property}
A low (in vowels), coronality (in consonants)
I high
U round
? occlusion (abrupt and sustained decrease in overall amplitude)
h noise (aperiodic energy)
L slack vocal cords / low tone
H stiff vocal cords / high tone
R coronality ${ }^{1}$
N nasality ${ }^{2}$
(a) velarity ${ }^{3}$

It needs to be observed that whenever a given segment is defined by means of more than one prime, one of the elements can perform the function of the expression head, whereas the others are operators / dependents. The head prime

1 Recently, the necessity to recognise the element $\mathbf{R}$ has been undermined in various studies. However, it is used both in KLV (1985) and Harris (1994). In the present work, we follow authors who represent coronality with $\mathbf{A}$.

2 In recent phonological studies attempts are being made to replace the nasal element with the low tone element $\mathbf{L}$, or rather fuse the two elements, for example Ritter (1997).

3 In fact, most $G P$-based analyses today have abandoned the neutral element and represent velarity as an empty head. 
specifies the salient property of the melody. In terms of its formal capabilities, the head licenses all the remaining primes constituting a segment. The combinatorial capabilities of elements are constrained by the so-called licensing constraints which are language-specific.

Furthermore, individual elements are organised under class nodes: the Root, Place/Resonance and Laryngeal. Consequently, a phonological process can involve either a single prime or target the whole class node, thus affecting all the elements gathered under it. The structure in (3) shows the geometric configuration of primes that potentially build phonological expressions (Harris (1994, 129)):

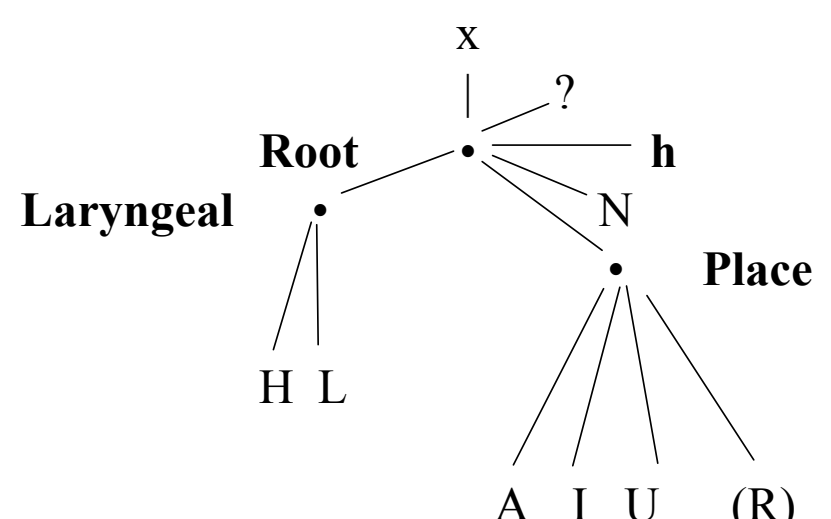

As mentioned above, each single prime corresponds to a unique, identifiable phonetic reality and when uttered in isolation, possesses its own unique manifestation. Below, a brief summary of the $G P$ proposals concerning the nature of elements and segments is presented:

* Elements are autonomous

* Segments are composed of elements

* Elements are fully interpretable at any stage of derivation

* Elements have unique phonetic manifestations

* Each element, when licensed, is directly linked to a skeletal position

* Elements can enjoy either head or operator status

* Elements are phonetically manifested once attached to a skeletal slot.

\subsection{The representation of turbulence}

Turning now to turbulent sounds, the basic prime that will concern us in their representation will be the $\mathbf{h}$ whose elemental pattern is defined as noise. Harris (1994, 123) explains that 'it maps onto the speech signal as aperiodic energy. The articulatory targeting of this effect involves a narrowed stricture which produces turbulent airflow.' The $\mathbf{h}$ prime is responsible for adding a noise 
component to obstruents, whereas sonorants, characterised by periodicity, will lack it. In fricatives and affricates, noise is commonly recognised as phonologically significant. However, the evidence concerning consonant lenition proves that $\mathbf{h}$ is phonologically active also in stops, characterising the release stage of genuine plosives. When manifested phonetically in isolation, the noise yields a glottal fricative. When paired with a place-defining prime, the latter will point to the location of the noise-producing gesture. Consequently, [s], for instance, will arise due to the combination of $\mathbf{h}$ with the resonance element $\mathbf{A}$ defining coronality, while [f] will be a fusion of $\mathbf{h}$ with $\mathbf{U}$.

Relying on the above insights, in (4) below the representations of German voiceless fricatives are depicted (partly based on Brockhaus $(1995,110)$ ):

$\begin{array}{ccccc}(4)^{4} & {[\mathrm{f}]} & {[\mathrm{s}]} & {[\mathrm{J}]} & {[\chi]} \\ & \mathrm{x} & \mathrm{x} & \mathrm{x} & \mathrm{x} \\ & \mid & \mid & \mid & \mid \\ & \mathrm{U} & \mathrm{R} / \mathrm{A} & \mathrm{I} & @ \\ \mid & \mid & \mid & \mid \\ \mathbf{h} & \mathbf{h} & \mathbf{h} & \mathbf{h} \\ \mid & \mid & \mid & \mid \\ \mathrm{H} & \mathrm{H} & \mathrm{H} & \mathrm{H}\end{array}$

The truly voiced series will contain the 'slack vocal cords' element $\mathbf{L}$ instead of H. The process of Final Obstruent Devoicing attested in the phonology of German will be represented as L-delinking, thus producing a neutral series without any laryngeal element. ${ }^{5}$

As regards affricate sounds, Harris (1994) treats them as contour structures, where a single melodic expression possesses one resonance node (element) and two root nodes, dominating the elements of occlusion and noise. This representation is provided in (5) below and can be applied to the structure of German affricates.

4 Recall that in the present study, $\mathbf{R}$ has been replaced with $\mathbf{A}$, whereas @ abandoned altogether.

5 For an extensive discussion of the $F O D$ phenomenon in the phonology of German, see Brockhaus (1995). 
(5)

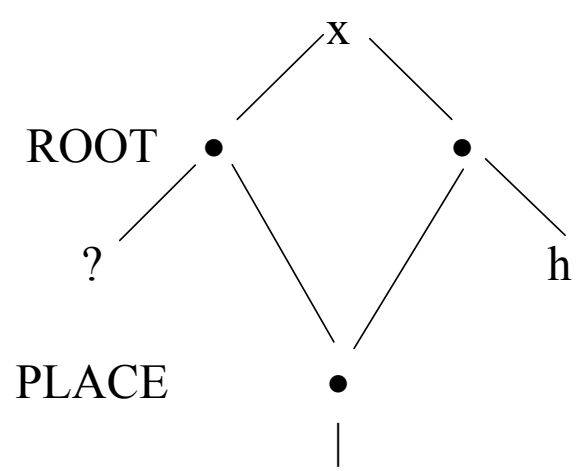

A

[ts]

Thus, the availability of two independent manner elements: occlusion and noise, each attached to a separate root node, will characterise the structure of all German affricates.

Keeping the above theoretical considerations in mind, let us turn to the processes of consonant degemination and the spirantisation of [g] in Modern Standard German which, on the one hand, point out to the necessity of recognizing the presence of the noise element in the representation of obstruents, and on the other, bring out the difference between fricatives and affricates in the system of German.

\section{Consonantal identity and the OCP effects}

As far as consonant degemination is concerned, the process involves the identity of the adjacent segments but not necessarily strict identity. Consequently, sequences of two [t]s or two [d]s will undergo reduction as readily as those of $[\mathrm{s}]+[\mathrm{z}]$ or $[\mathrm{d}]+[\mathrm{t}]$. To illustrate the process of degemination, a number of examples are provided in $(6):^{6}$

$\begin{array}{lll}\text { (6) }) \text { rät } & \text { [RE:t }] & \text { 'he advises' } \\ \text { (er) lädt } & \text { [1E:t }] & \text { 'he loads' } \\ \text { (du) liest } & \text { [li:st }] & \text { 'you read' } \\ \text { Nam }+ \text { en }+n> & \text { Nam+en } & \text { 'name/dat.pl.', } \\ \text { Orden }+n> & \text { Orden } & \text { 'order/dat.pl.' } \\ \text { Esel+lein }> & \text { Eselein } & \text { 'donkey/dim.' }\end{array}$

6 The evidence has been taken from Wiese (1996, 230-231). Following Wurzel (1970) and Lieber (1987), Wiese $(1996,230)$ assumes that 'all nouns in their plural form (except for those plural-marked by /-s/) receive a suffix /-n/ as a marker for the dative case'. Thus, in Namen, for instance, the first [n] signifies plurality, whereas the second one the dative case. 
wahl+los

un+nahbar 'indiscriminately'

'unapproachable'

The handful of illustrative examples supplied above are those where degemination is either an obligatory or preferred outcome. Below in (7), we present a list summarising degemination-displaying contexts (based on Wiese (1996)):

(7) The contexts of degemination

a. in verbal inflection, in a sequence of identical coronals

b. in noun inflection, in a sequence created by the dative marker $/ \mathrm{n} /$ and [n]ending nouns

c. in the suffixation of the diminutive /-lein/ to a syllable ending in [1] and whose nucleus dominates schwa

d. in compounds and prefixation in a sequence of identical consonants

What needs to be added at this point is that the suffixation of a verbal ending opening with a segment identical with that of the root does not always exhibit the degemination effect. For a change, in some verbal forms, schwa epenthesis is attested. Consider forms such as:
(er) wartet
[vartwt] 'he waits'
(er) endet
[Endwt]
'he finishes'
(sie) berichtet
[bW\} rç'twt] 'she informs'

Interestingly, in the case of affricates, consonant reduction will affect only those affricate-final verbs which are followed by a suffix beginning with $[\mathrm{s}]$ and $[\mathrm{z}]$ but never with [t] or [d]. In the present analysis we shall argue that the peculiar behaviour of affricates indicates a specific role of the manner-defining elements in the process of degemination. It will be maintained that the primes in question contract special binding relations which make them susceptible to the operation of the Obligatory Contour Principle. Before we unfold the details of the analysis, however, let us look at the evidence illustrating the behaviour of affricates with respect to degemination (Wiese (1996: 41)):

$\begin{array}{llll}\text { sitzt } / \text { zits } /+/ \text { st } / & > & \text { [zitst }] & \text { 'sit } / 2 \text { sg. pres.' } \\ \operatorname{tanzt} / \operatorname{tants} /+/ \text { st } / & > & {[\text { tantst }]} & \text { 'dance } / 2 \text { sg. pres.' } \\ \operatorname{tanzt} / \operatorname{tants} /+/ \mathrm{t} / & > & {[\text { tantst }]} & \text { 'dance } / 3 \text { sg. pres.' }\end{array}$

Summarising the facts about consonant degemination in German, we need to observe that the cluster simplification occurs when consonants are identical and 
strictly adjacent on the melodic plane. Interestingly, however, complete identity is not expected for reduction to take place. Above all, degemination seems insensitive to the voicing specifications of the segments involved. What is important, however, sequences of affricates and following fricatives are regarded as identical. On the other hand, affricates followed by stops behave as distinct units by resisting the simplifying effects. Another significant requirement for degemination to occur is that the melodies affected by the process must be separated by an empty nucleus. ${ }^{7}$ Should we be having a schwa intervening between them, no degemination will ever be found. Thirdly, we need to observe a correlation between the presence of consonant degemination and the effect of vowel umlaut, which, because of its multi-aspectual nature, will not be studied in detail here.

A GP-based account of consonant degemination is tightly connected with the operation of the Obligatory Contour Principle (Goldsmith (1976; 1990), McCarthy (1986)) which as a strong cross-linguistic tendency enforces the reduction of identical segment sequences whose members are adjacent on the melodic level. Language-specific $O C P$ effects reveal that identity can mean different things in different systems. In some languages, the $O C P$ will target segments whose elemental make-up is identical, whereas in others, it is sufficient for adjacent melodies to share only a subset of primes, e.g. head elements (as in Japanese (Yoshida (1991)), ${ }^{8}$ to become liable to the OCP reduction. In German, cluster simplification is naturally induced by the complete identity of the segments that are immediately adjacent in the melodic plane. In consequence, sequences of $[\mathrm{t}] \mathrm{s}$, [d]s, [s]s or [z]s will be reduced to single occurrences of these melodies. A more interesting situation arises when the $O C P$ becomes triggered in the case of affricate - fricative strings yet blocked whenever affricate - stop sequences are encountered. The autosegmental mode of representation and the geometry of prime configuration advocated by Government Phonology make it possible for us to account for that discrepancy in the behaviour of different obstruent strings. The difference in question can be illustrated with two structures of tantzt, one being the realisation of the $2 \mathrm{sg}$. pres. and the other manifesting the $3 \mathrm{sg}$. pres. of tantzen 'dance'. Notice that in the former, the fricative [s] deletes as a result of the $O C P$ requirements, whereas

7 Government Phonology recognises the possibility of the presence of empty positions in the phonological representation. An empty position is a timing slot unattached to any melodic material. In order to remain phonetically unrealised, this slot has to be either licensed by parameter (e.g. word-finally) or properly governed (the Empty Category Principle).

8 In Connemara Irish segments which share manner-defining primes are considered as identical (Bloch - Rozmej (1998)). 
no such phenomenon is observed in the latter. Below we depict the effect of degemination:

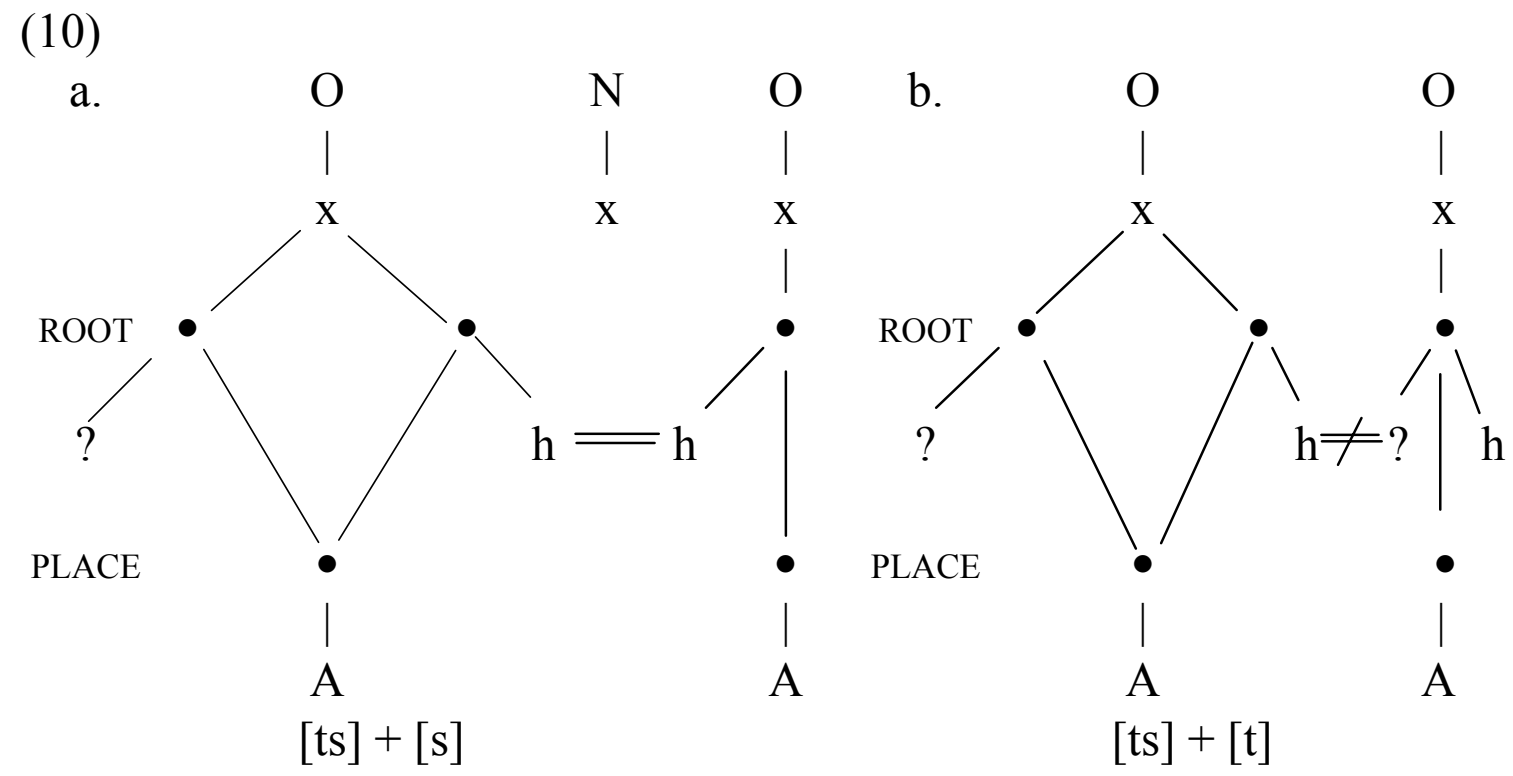

Looking at the above structures, one cannot fail to observe that in (10a) in the sequence of an affricate followed by a fricative, the noise elements (h) are strictly adjacent unlike in (10b), where noise borders on occlusion. Since the $O C P$ reduction effect targets the former, we have to conclude that German interprets sequences of homorganic affricates and fricatives as identical. Consider (11) below:

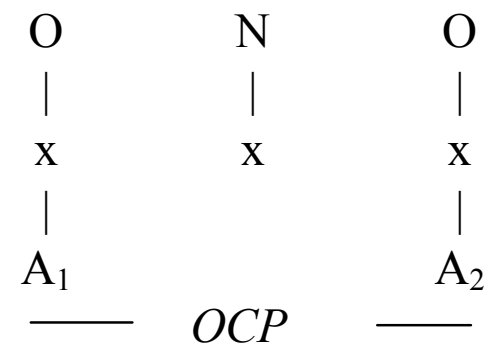

$A_{1}$ and $A_{2}$ have the same Root elements.

The schematic structure in (11) reveals that in German a hypothesis can be issued to the effect that two immediately adjacent segments whose mannerdefining elements (noise) gathered under the Root nodes are the same are regarded as identical. Furthermore, the analysis offered in Bloch-Rozmej (2002) formulates another important condition that has to be satisfied for the $O C P$ to be triggered. More specifically, the noise or occlusion primes residing in neighbouring melodies have to contract a specific bridging relation, which represents a special type of licensing, that has the capacity to expose the two elements to the operation of the $O C P$. Support for the existence of interelement 
bridging in German comes from the observed correlation between degemination and Umlaut. ${ }^{9}$ In brief, the manner elements will be capable of entering into a bridging relation once a nuclear position separating them remains empty. Otherwise, should schwa appear between them, which is interrelated with the occurrence of the stem vowel umlaut, no bridging is found and hence no degemination is attested. Compare (er) rät [RE:t] 'he advises' and (er) wartet [vartWt] 'he waits'. In the former, the stem vowel [a] is umlauted to [E], which correlates with an absence of schwa in the verbal suffix and degemination of the [tt] cluster. In [vartWt], on the other hand, the root vowel remains unchanged and hence schwa is realised in the suffix, thus preventing the degemination of the consonant sequence.

In what follows, we shall look into the problem of consonant spirantisation attested in German words which sheds some light on the exceptional character of manner elements in this language.

\section{The process of spirantisation}

Within the model of Government Phonology, spirantisation represents one of the weakening processes. Harris (1994) mentions the following opening trajectories resulting in segment decomposition:

(12) Opening trajectories (Harris, 1994: 120)

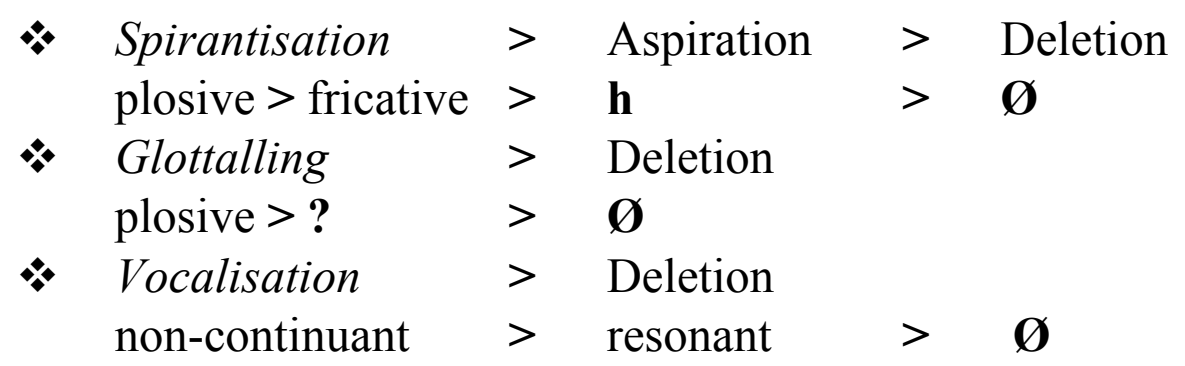

Turning now to the process of [g]-spirantisation, it has to be noted that it reveals new facts concerning a special status of the turbulence-defining prime as well as that of occlusion in the phonology of German. More specifically, when promoted to the status of the segment head, the primes are interpreted as contributing to their phonetic manifestation their salient phonetic properties of both noise and voicing. Additionally, there emerges a significant difference between the dialects of German with reference to consonant weakening, instantiated by spirantisation. It is significant that Northern Standard German

9 This problem has been analysed in detail in Bloch-Rozmej (2002). Because of its great complexity, the question of Umlaut in German will not be dealt with in the present study. 
(NSG) differs from Hochlautung with respect to the spirantisation of devoiced velar stops. While Hochlautung seems to have no truly general spirantisation process, NSG speakers 'systematically spirantise all those underlyingly voiced velar stops which occur in FOD environments' (Brockhaus (1995: 252)). ${ }^{10}$ Once again, we shall adhere to the mechanism of element bridging to account both for the process of spirantisation and its correlation with final devoicing. Evidence illustrating the process of spirantisation is provided in (13) (based on Wiese (1996)):

$\begin{array}{lll}\text { (13) } \begin{array}{ll}\text { Tei }[\AA] \\ \text { Zwei }[\AA]\end{array} & \text { Tei[g]e } & \text { 'dough/pl.' } \\ \text { but } & \text { Zwei[g]e } & \text { 'branch/pl.' } \\ \text { Tei }[\AA] & & \\ & \text { Teiche } & \text { 'pond/pl.' }\end{array}$

Thus, $[\mathrm{g}]$ is subject to spirantisation and becomes turned into a palatal fricative if preceded by [i] and word-finally. The change is not reserved for the suffix /ig/ exclusively. In the formal register of Modern Standard German, the nonsyllabic [i'] (as in Teig, or Zweig) will not trigger the spirantisation of the following velar. Nonetheless, in northern colloquial speech, the narrow context for spirantisation includes also the non-syllabic [i'], other vowels than [i] and even consonantal contexts.
(14) $\mathrm{We}[\AA]$
$\mathrm{We}[\mathrm{g}] \mathrm{e}$
'way/pl.'
$\mathrm{Zu}[\mathrm{X}]$
$\mathrm{Zü}[\mathrm{g}] \mathrm{e}$
'train/pl.'
$\mathrm{Ta}[\mathrm{X}]$
$\mathrm{Ta}[\mathrm{g}] \mathrm{e}$
'day/pl.'
$\operatorname{Sar}[\AA]$
Sär[g]e
'coffin/pl.'

The alternations depicted in (13) and (14) above point out that the lexical realisation of the palatal fricative must be [g]. In terms of segment-internal changes as perceived by $G P$, spirantisation will consist in the delinking of the occlusion prime. It is also noteworthy that lexical voiceless velar stops do not subdue themselves to spirantisation (Brockhaus (1995: 253)), e.g:
(15) buk [bu:k]
'(he/she/it) baked'
Pik [pi:k]
'spades' (cards)

This can indicate that their phonological constitution in terms of elemental material should be different. One hypothesis aiming at resolving this problem is that proposed by Brockhaus (1995) introducing a lexical distinction between

10 Recall that FOD stands for 'final obstruent devoicing'. 
truly voiced stops and truly voiceless ones by assigning the $\mathbf{L}$ element to the former and $\mathbf{H}$ to the latter. In such a case, spirantisation will be analysed as the delinking of the $\mathbf{L}$ element and occlusion in the context characteristic of FOD, i.e. before a word-final empty nucleus, and the following [i]. This situation is depicted in (16) below:

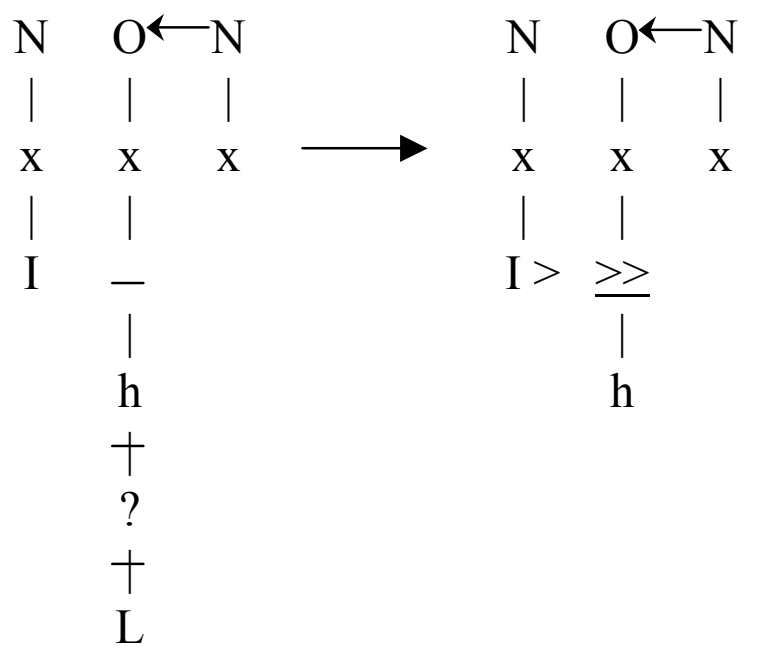

Government Phonology recognises the position licensed by an empty word-final nucleus, which because of its lack of melodic material is the weakest licenser, as one of the primary lenition sites. Hence, elements that have not been autosegmentally licensed, i.e., $\mathbf{L}$ and ? undergo detachment from their skeletal position, and in consequence, remain unrealised phonetically. As a result of that operation, the noise element becomes the sole resident of the consonantal structure, which is realised as a voiceless spirant. Simultaneously, in the dialect where a high front vowel precedes the lenition site, the palatal prime I spontaneously spreads into the head position of the spirant, which is realised as $[\AA]$ (a voiceless palatal fricative).

When analysing the change of the voiced velar plosive into a voiceless palatal fricative, three separate steps can be distinguished: devoicing, spirantisation and palatalisation. However, as observed before, the loss of the occlusion element necessarily accompanies the delinking of $\mathbf{L}$. In other words, spirantisation and final devoicing apply in a joint manner, both being instances of segmental weakening. We have identified the trigger of the lenition as a final empty nucleus, an inherently weak prosodic licenser. GP proposes that a phonological process targets one prime at a time, which in the light of the facts concerning spirantisation, whereby two primes become delinked from the slot, suggests that both elements can be intimately related. In fact, we shall argue that the loss of both primes represents the same mechanism. Moreover, we should keep in mind that in the autosegmental mode of representation primes are autonomous in the sense of the absence of mutual conditioning of elements' 
behaviour. This requirement, however, seems to be violated in the case of spirantisation since the detachment of occlusion is always bound up with the loss of the laryngeal element.

To resolve this dilemma, the present analysis proposes that in German the voicing dimension of segments should be represented as headedness. More precisely, the occurrence of the occlusion element in the head position of a given melody is interpreted simultaneously as both stopness and voice. Therefore, in NSG voiceless consonants are either underlyingly marked for the $\mathbf{H}$ element or when H-less, possess occlusion in other than the head position. Voicing, on the other hand, will be the absence of $\mathbf{H}$ on the one hand, and the headedness of the manner element on the other. These proposals will be illustrated with the contrast among $[\mathrm{k}] /[\mathrm{g}]$ and $[\mathrm{X}]$.

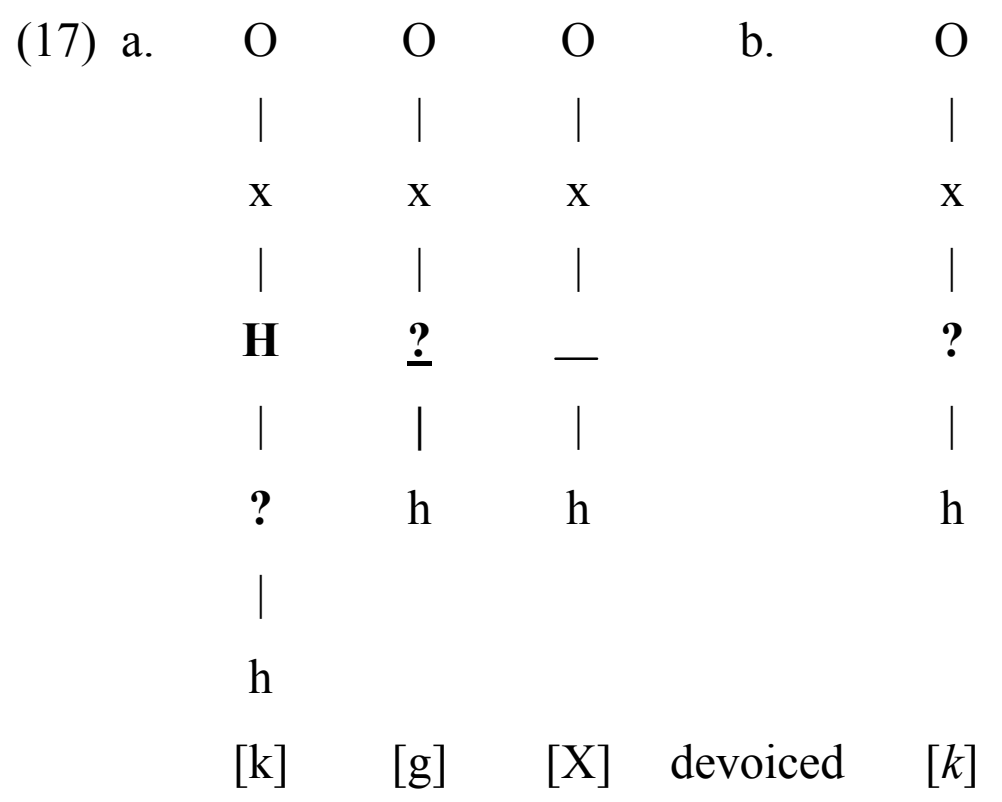

In Northern Standard German voiced segments will lack the $\mathbf{H}$ element and one of the manner elements will occupy the head position. Such melodies will be attested in environments other than those typical of FOD. In these sites spirantised variants occur. By representing the voiced velar plosive as a segment in which the headedness of ? manifests itself as voicing, we are able to account for both devoicing and spirantisation by means of one operation. Specifically, the licensing of this segment by an empty nuclear position confers too little autosegmental potential to occlusion, thus causing its delinking. ${ }^{11}$ This, in turn,

11 The autosegmental licensing potential is conferred by a licenser onto a licensee. Consequently, depending on the strength of the licenser, the number of the elements capable of being sanctioned by the licensed position, will be directly contingent on the amount of the potential that this position is endowed with. Melodically-filled positions will be considered as normally stronger licensers than empty ones. 
produces a spirant and simultaneously devoices the melody as the manner element ceases to be the head. Since in NSG spirantisation is optional, in cases where only devoicing occurs, the manner element will become demoted to the dependent status without being detached from the skeletal position. This will produce a headless and hence voiceless plosive.

Finally, let us observe that German has two dorsal spirants $[\AA]$ and $[\mathrm{X}]$, either of them being a potential outcome of spirantisation, depending on the dialect. In terms of contextual realisation, $[\AA]$ is invariably found after a palatal glide or a front vowel, while $[\mathrm{X}]$ is attested following a back vowel or glide. Distributionally, the manifestation of the velar fricative appears more severely restricted. Its dependence on the occurrence of the preceding back vowel reflects a phonological backness sharing generalisation operative in German. Precisely, this condition is put forward in Gussmann (2002: 61) as German Backness Sharing.

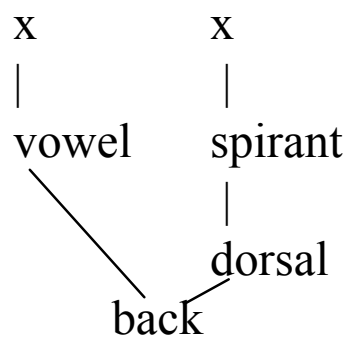

The palatal fricative, on the other hand, occurs in the remaining contexts Therefore, it can be maintained, as in Gussmann (2002), that $[\AA]$ is merely a phonetic effect.

\section{Conclusion}

Government Phonology represents the quality of turbulence with an independent phonological prime of noise which is defined as aperiodic energy. Apart from contributing its unique phonetic characteristics to the interpretation of fricative and affricate sounds, noise, similar to occlusion, can enjoy the status of the segment head that is capable of performing language-specific roles.

The analyses of the two processes of degemination and spirantisation emphasise the importance of the manner-defining elements in the representation of fricatives and affricates, their specific function in the melodic plane, i.e. a possibility to become segment heads with the accompanying effect of voicing, and possibilities of contracting special types of licensing/bridging relations that bring about significant changes in the phonetic manifestation of the relevant segments, e.g. leading to the $O C P$-enforced reduction effects. Noise and occlusion sharing (bridging) that obtains between melodically adjacent 
consonants is interpreted as the identity of the segments involved, thus triggering the $O C P$.

\section{References}

Bloch-Rozmej, Anna (1998). Element Interactions in Phonology. A Study in Connemara Irish. Lublin: Redakcja Wydawnictw KUL.

Bloch-Rozmej, Anna (2002). Degemination in German. In: Elżbieta Mańczak-Wohlfeld (ed.). Proceedings of the $10^{\text {th }}$ Annual Conference of the Polish Association for the Study of English. Kraków: Jagiellonian University Press, $11-21$.

Brockhaus, Wiebke (1995). Final Devoicing in the phonology of German. Tübingen: Max Niemeyer Verlag.

Goldsmith, John A. (1976). An Overview of Autosegmental Phonology. Linguistic Analysis 2, $23-68$.

Goldsmith, John A. (1990). Autosegmental and Metrical Phonology. Oxford: Blackwell.

Gussmann, Edmund (2002). Phonology. Analysis and Theory. Cambridge: Cambridge University Press.

Harris, John (1994). English Sound Structure. Oxford: Blackwell Publishers.

Kaye, Jonathan, Lowenstamm, Jean and Vergnaud, Jean-Roger (1985). The Internal Structure of Phonological Elements: a Theory of Charm and Government. Phonology Yearbook $2,305-328$.

Kaye, Jonathan, Lowenstamm, Jean and Vergnaud, Jean-Roger. (1990). Constituent Structure and Government in Phonology. Phonology 7, $193-231$.

Lieber, Rochelle, (1987). An Integrated Theory of Autosegmental Processes. Albany, NY: State University of New York Press.

McCarthy, John (1986). OCP Effects: Gemination and Antigemination. Linguistic Inquiry 17, $207-63$.

Ritter, Nancy (1997). Headedness as a means of encoding stricture. In: G. Booij and J. van de Weijer (eds.). Phonology in progress - progress in phonology. The Hague: Holland Academic Graphics. 333 - 365.

Wiese, Richard (1996). The Phonology of German. Oxford: Clarendon Press.

Wurzel, Wolfgang, U. (1970). Studien zur deutschen Lautstruktur. Berlin: Akademie-Verlag.

Yoshida, Shohei (1991). Some Aspects of Governing Relations in Japanese Phonology. Doctoral dissertation, London: London School of Oriental and African Studies. 